Meталлофиз. новейшие технол. / Metallofiz. Noveishie Tekhnol. (C) 2014 ИМФ (Институт металлофизики 2014 , т. 36, № 11, сс. 1453-1463

Оттиски доступны непосредственно от издателя

им. Г. В. Курдюмова НАН Украины)

Фотокопирование разрешено только

Напечатано в Украине.

в соответствии с лицензией

PACS numbers: 75.30.Et, 75.30.Gw, 75.50.Ee, 75.70.Cn, 75.80.+q, 85.70.Ay

\title{
The Anisotropy Induced by a Magnetostriction in Exchange-Biased Two-Layer Films
}

\author{
O. V. Gomonay and I. Lukyanchuk* \\ Institute of Physics \& Technology, \\ National Technical University of Ukraine ' $K P I$ ', \\ 37 Peremogy Avenue, \\ 03056 Kyiv, Ukraine \\ "Laboratory of Cond. Mat. Physics, \\ University of Picardy (LPMC-UPJV), \\ 33 Rue Saint-Leu, \\ 80039 Amiens, France
}

The exchange bias at ferromagnetic (FM)/antiferromagnetic (AF) interfaces strongly depends upon the state of antiferromagnetic layer, which is sensitive to mechanical stresses due to its strong magnetoelastic coupling. In a given paper, we consider magnetoelastic effects, which arise at FM/AF interface due to misfit of lattices and magnetic ordering. We show how magnetostriction affects mutual orientation of the AF and FM vectors as well as magnetic easy-axis direction in thin AF layer. The results obtained can be used for tailoring of exchange-biased systems.

Величина обмінного підмагнетовування на межі поділу феромагнетик (ФМ)/антиферомагнетик (АФ) істотно залежить від стану антиферомагнетного шару, який, завдяки сильним магнетопружнім взаємодіям, чутливий до механічних напружень. В даній роботі розглянуто магнетопружні ефекти, що виникають на межі поділу ФМ/АФ через гратницеву невідповідність і магнетне впорядкування. Продемонстровано спосіб, в який магнетострикція впливає на взаємну орієнтацію АФ- і ФМ-векторів і на напрямок легкої осі в тонкому АФ-шарі. Одержані результати можуть бути використаними при створенні систем з обмінним підмагнетовуванням.

Величина обменного подмагничивания на границе раздела ферромагнетик (ФМ)/антиферромагнетик (АФ) существенно зависит от состояния антиферромагнитного слоя, который, благодаря сильным магнитоупругим взаимодействиям, чувствителен к механическим напряжениям. В данной статье рассмотрены магнитоупругие эффекты, возникающие на границе

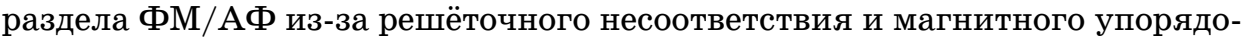
чения. Показано, каким образом магнитострикция влияет на взаимную 
ориентацию АФ- и ФМ-векторов и на направление лёгкой оси в тонком АФ-слое. Полученные результаты могут быть использованы при создании систем с обменным подмагничиванием.

Key words: magnetic anisotropy, exchange bias, magnetoelasticity, magnetic properties of interfaces, antiferromagnet.

(Received April 7, 2014)

\section{INTRODUCTION}

Antiferromagnetic (AF) materials are widely used in spintronic devices as auxiliary elements for pinning of ferromagnetic (FM) magnetization through the effect of exchange bias (see, e.g. [1]). The possibility to control the state of coupled AF/FM bilayers requires investigation of the magnetic mechanisms that could be responsible for bias effect. Many researchers [2-7] emphasize the important role of the AF domain structure in the establishing of the exchange bias. The problem of AF domains is intimately related with magnetoelastic coupling [8] and can strongly depend upon the mechanical stress that appears at the FM/AF interface due to the lattice misfit. Magnetostriction can also provide additional coupling between FM and AF layers and affect orientation of AF moments in the near-surface region $[9,10]$. The widely studied epitaxial films consisting of FM and nonmagnetic materials [11-14] show strong correlation between magnetoelastic coupling and magnetic properties. Analogous and even more striking phenomena could be expected in the systems, which combine FM with AF that possesses large magnetostriction.

In the present paper, we show that magnetostriction of AF produces uniaxial anisotropy in the plane of the adjacent FM layer and, thus, causes strong surface magnetic anisotropy in AF itself.

\section{UNIAXIAL ANISOTROPY OF FERROMAGNET}

Epitaxial ferromagnetic film deposited on top of AF inherits the crystallographic structure of the substrate. If the substrate has a certain anisotropy induced by magnetoelastic strains, this anisotropy in atomic arrangement will be reproduced by the FM layer. Thus, additional contribution to the magnetic energy of film should be proportional to magnetoelastic coupling in both FM and AF materials. Phenomenological expression for such a type of uniaxial in-plane anisotropy can be deduced from the magnetoelastic energy of FM, which for a cubicsymmetry crystal is as follows:

$$
f_{m e}^{F}=b_{1}^{F}\left(u_{x x} \alpha_{x}^{2}+u_{y y} \alpha_{y}^{2}+u_{z z} \alpha_{z}^{2}\right)+2 b_{2}^{F}\left(\alpha_{x} \alpha_{y} u_{x y}+\alpha_{y} \alpha_{z} u_{y z}+\alpha_{z} \alpha_{x} u_{z x}\right) .
$$


Here, $u_{i k}$ are strain tensor components, which we calculate with respect to the bulk nonmagnetic reference state, $b_{1,2}^{F}$ are magnetoelasticcoupling coefficients. Magnetisation vector $\mathbf{M}_{\mathrm{F}}$ of $\mathbf{F M}$ is described by the direction cosines $\alpha_{k}, k=x, y, z$. In the relaxed state of FM/AF system, an equilibrium strain $u_{i k}$ includes deformations produced by lattice mismatch and spontaneous strain $\hat{u}_{\text {mag }}$ induced by magnetic ordering in the AF substrate. For a symmetric (001) surface, the misfitinduced strains are isotropic and can influence only out-of-plane anisotropy of FM. In contrast, magnetostrictive contribution, though small as compared with the misfit strain, has nontrivial shear components, $u_{x x}^{\mathrm{AF}}-u_{y y}^{\mathrm{AF}}$ and/or $u_{x y}^{\mathrm{AF}}$ which can remove degeneracy between different in-plane directions. Thus, uniaxial contribution into magnetocrystalline energy of FM film takes a form

$$
f_{u a}^{\mathrm{F}}=\frac{1}{2} K_{1 u a}^{\mathrm{F}} \rho_{j}\left(\alpha_{x}^{2}-\alpha_{y}^{2}\right)+K_{2 u a}^{\mathrm{F}} \rho_{j} \alpha_{x} \alpha_{y}
$$

with anisotropy constants

$$
K_{1 u a}^{\mathrm{F}}=b_{1}^{\mathrm{F}}\left(u_{x x}^{\mathrm{AF}}-u_{y y}^{\mathrm{AF}}\right), K_{2 u a}^{\mathrm{F}}=2 b_{2}^{\mathrm{F}} u_{x y}^{\mathrm{AF}} .
$$

Variable $\rho_{j}= \pm 1$ distinguishes between the different domains of AF.

A preferable direction of FM magnetisation $\mathbf{M}_{\mathrm{F}}$, which depends upon the sign of the coefficients $K_{u a}^{\mathrm{F}}$, is defined by correlation between selfstriction of the FM and external striction imposed by the AF. If, for example, magnetostriction of FM in the direction of magnetisation is positive (elongation, $b^{\mathrm{F}}<0$ ), $\mathbf{M}_{\mathrm{F}}$ will tend to align in the direction of maximal elongation of the $\mathrm{AF}$, i.e., for positive $u^{\mathrm{AF}}$ value (elongation), $K_{u a}^{\mathrm{F}}$ is negative, as can be easily checked from equation (3).

Magnetostriction-induced uniaxial anisotropy (3) competes with the anisotropy arising from the FM/AF exchange in a thin near-surface region of thickness $\xi$. For a compensated AF surface, this contribution depends upon the exchange integral between the atoms of FM and AF, $J_{\mathrm{F}-\mathrm{AF}}$, and susceptibility of AF, $\chi_{\mathrm{AF}} \equiv 1 / J_{\mathrm{AF}}$ (Koon's model, [15]):

$$
f_{\text {exch }}=-\frac{1}{2} \chi_{\mathrm{AF}} J_{\mathrm{F}-\mathrm{AF}}^{2}\left[\mathbf{M}_{\mathrm{F}} \times \mathbf{L}_{S}\right]^{2} .
$$

The AF vector $\mathbf{L}_{S}$ describes orientation of spins at the surface of the $\mathrm{AF}$ substrate (which in principle can differ from that in the bulk, as will be shown later).

To elucidate the effect of both contributions, let us consider a simple case when one of the in-plane easy axes (say, $x$ ) of FM coincides with inplane $\mathbf{L}_{S}$ direction and $u_{x y}^{\mathrm{AF}}=0$. For the in-plane FM ordering $\left(\alpha_{z}=0\right)$, we set $\alpha_{x}=\cos \psi, \alpha_{y}=\sin \psi$. Thus, the effective energy is 


$$
f_{\mathrm{eff}}^{\mathrm{F}}=\frac{1}{4} K_{4} \sin ^{2} 2 \psi+\frac{1}{2}\left[K_{u a} \rho_{j}+\frac{\xi}{2 t_{\mathrm{F}}} \chi_{\mathrm{AF}} J_{\mathrm{F}-\mathrm{AF}}^{2}\right] \cos 2 \psi .
$$

Constant $K_{4}>0$ is magnetocrystalline constant, and we suppose the FM film to be homogeneously ordered throughout the thickness $t_{\mathrm{F}}$.

Equilibrium value $\psi=\psi^{\mathrm{eq}}$ minimizes effective energy (5), so, it satisfies the relations

$$
\begin{gathered}
\sin 2 \psi^{\mathrm{eq}}\left\{K_{4} \cos 2 \psi^{\mathrm{eq}}-\left[K_{u a} \rho_{j}+\frac{\xi}{2 t_{\mathrm{F}}} \chi_{\mathrm{AF}} J_{\mathrm{F}-\mathrm{AF}}^{2}\right]\right\}=0 . \\
K_{4} \cos 4 \psi^{\mathrm{eq}}-\left[2 K_{u a} \rho_{j}+\frac{\xi}{t_{\mathrm{F}}} \chi_{\mathrm{AF}} J_{\mathrm{F}-\mathrm{AF}}^{2}\right] \cos 2 \psi^{\mathrm{eq}}>0 .
\end{gathered}
$$

In the absence of FM/AF interaction, FM has two equivalent easy directions in (001) plane, $\psi_{1}^{(0)}=0$ and $\psi_{2}^{(0)}=\pi / 2$. Antiferromagnetic substrate removes this degeneracy. If exchange coupling is not too large, $\xi \chi_{\mathrm{AF}} J_{\mathrm{F}-\mathrm{AF}}^{2} \leq K_{4} t_{\mathrm{F}}$, both solutions $\psi_{1,2}^{\mathrm{eq}}$ satisfy equations (6), but have different energies, the difference being

$$
f_{\mathrm{eff}}^{\mathrm{F}}\left(\psi_{1}^{\mathrm{eq}}\right)-f_{\mathrm{eff}}^{\mathrm{F}}\left(\psi_{2}^{\mathrm{eq}}\right)=K_{u a} \rho_{j}+\frac{\xi}{2 t_{\mathrm{F}}} \chi_{\mathrm{AF}} J_{\mathrm{F}-\mathrm{AF}}^{2} .
$$

It can be easily seen from (8) that the FM/AF exchange coupling makes favourable the solution with $\mathbf{M}_{F} \perp \mathbf{L}_{S}\left(\psi_{2}^{\mathrm{eq}}=\pi / 2\right.$ ) for any sign of the exchange constant $J_{\mathrm{F}-\mathrm{AF}}$. In turn, magnetostriction-induced anisotropy $K_{u a}$ can oppose this tendency and can make preferable in-parallel orientation of $\mathbf{M}_{\mathrm{F}}$ and $\mathbf{L}_{S}\left(\psi_{1}^{\mathrm{eq}}=0\right)$. It should be stressed that these two mechanisms have different origin and the system can switch from one easy-axis to another with variation of FM thickness. Exchange mechanism ties together mutual orientation of FM magnetisation and AF spins in the near-surface layer. This mechanism is important for very thin films, where factor $\xi / t_{\mathrm{F}}$ is not vanishingly small. Magnetostriction-related mechanism is a long-range one; it depends upon orientation of AF moments in the bulk, which can be different from $\mathbf{L}_{S}$. Moreover, in some AFs widely used in $\mathrm{FM} / \mathrm{AF}$ systems (e.g., $\mathrm{NiO}, \mathrm{CoO}$, $\mathrm{LaFeO}_{3}, \mathrm{KCoF}_{3}$ ), magnetostriction originates from the strong spatial dependence of the exchange integral and is insensitive to exact orientation of AF spins. In this very important case, uniaxial anisotropy of FM is defined mainly by the domain structure of AF.

The role of magnetostriction-induced mechanism can be illustrated by some experimental examples. Simultaneous observation of the FM and $\mathrm{AF}$ spins in $\mathrm{Co} / \mathrm{LaFeO}_{3}$ [16] and $\mathrm{Co} / \mathrm{NiO}$ [17] systems revealed that FM magnetisation is aligned parallel or antiparallel to the in-plane projection of the AF axis in contrast to the usually observed perpendicular 
coupling consistent with the Koon's model [15]. Uniaxial anisotropy is also detected after deposition of Fe on top of $\mathrm{KCoF}_{3}[18,19]$. All these AFs are known to have rather large magnetostriction of the exchange nature (see Table 1).

Using the values of magnetoelastic constants for ferromagnets (Table 2), one can calculate from equation (3) the expected value of uniaxial anisotropy in different FM/AF combinations (see Table 3).

As can be seen from Table 3, uniaxial anisotropy in the Fe film constitutes only $\cong 10 \%$ from the 'pure' magnetic anisotropy. Nevertheless, this value will last to choose preferable axis of magnetisation as was clearly observed in the experiments $[18,19]$.

TABLE 1. Magnetostriction (spontaneous deformations) of typical AFs calculated from the experimentally observed lattice constants above and below Néel temperature.

\begin{tabular}{c|c}
\hline $\mathrm{AF}$ & Magnetostriction \\
\hline $\mathrm{NiO}$ & $-2.6 \cdot 10^{-3}[20]$ \\
$\mathrm{LaFeO}_{3}$ & $-4.76 \cdot 10^{-4}[21]$ \\
$\mathrm{KCoF}_{3}$ & $-2.0 \cdot 10^{-3}[22,23]$ \\
$\mathrm{CoO}$ & $-2 \cdot 10^{-2}[24]$ \\
\hline
\end{tabular}

TABLE 2. Magnetoelastic coupling coefficients for FMs [11] (in [ $\left.\mathrm{erg} / \mathrm{cm}^{3}\right]$ ).

\begin{tabular}{c|c|c}
\hline & Co, f.c.c. & Fe, b.c.c. \\
\hline$b_{1}$ & $-9.2 \cdot 10^{7}$ & $-3.43 \cdot 10^{7}$ \\
$b_{2}$ & $7.7 \cdot 10^{7}$ & $7.83 \cdot 10^{7}$ \\
\hline
\end{tabular}

TABLE 3. Magnetic anisotropy of systems $\left[\mathrm{erg} / \mathrm{cm}^{3}\right] . K_{4}\left(2^{\text {nd }}\right.$ column $)$ is the 4 th order magnetocrystalline anisotropy observed in the bulk Fe and Co crystals. Theoretical values of $K_{u a}$ (third column) are calculated from Eq. (3). Experimental values of $K_{u a}$ (the last column) are extracted from measurement of hysteresis loops (for $\mathrm{Co}$ ) and ferromagnetic resonance (for $\mathrm{Fe}$ ).

\begin{tabular}{c|c|c|c}
\hline \multirow{2}{*}{ FM/AF system } & \multirow{2}{*}{$K_{4}$} & \multicolumn{2}{|c}{$K_{u a}$} \\
\cline { 3 - 4 } & & Theory & Experiment \\
\hline $\mathrm{Co} / \mathrm{NiO}$ & $-2.3 \cdot 10^{5}[26]$ & $2.0 \cdot 10^{5}$ & $1.8 \cdot 10^{5}[27]$ \\
$\mathrm{Co} / \mathrm{LaFeO}_{3}$ & & $0.37 \cdot 10^{5}$ & $1.4 \cdot 10^{5}[16]$ \\
$\mathrm{Co} / \mathrm{CoO}$ & & $6.0 \cdot 10^{6}$ & $1.2 \cdot 10^{6}[28]$ \\
$\mathrm{Fe} / \mathrm{NiO}$ & $8.5 \cdot 10^{5}[12,19]$ & $0.9 \cdot 10^{5}$ & - \\
$\mathrm{Fe} / \mathrm{KCoF}_{3}$ & & $0.7 \cdot 10^{5}$ & $0.8 \cdot 10^{5}[19]$ \\
\hline
\end{tabular}


More pronounced effect is expected in Co films, which have rather high magnetostriction and small bulk magnetic anisotropy. Predicted value of the uniaxial anisotropy is of the same order as $K_{4}$ or even one order of magnitude larger, than in the case of $\mathrm{Co} / \mathrm{CoO}$. It should be noted that in calculation we started from the bulk values of magnetoelastic coefficients for $\mathrm{Fe}$ and $\mathrm{Co}$. In the case of ultrathin Co films, these values need to be ascertained because of the large potential misfit between FM and AF lattices (nearly 10\%). Depending on the growth mode, this mismatch can either relax through the formation of dislocations, or produce strong internal stresses in the Co film, which, in turn, can give rise to a crucial change of the value and even the sign of magnetoelastic coefficient (see, e.g., Refs. [13, 25]).

\section{SURFACE ANISOTROPY OF ANTIFERROMAGNET}

It is widely recognised that lattice misfit strongly influences the magnetic and magnetoelastic properties of the film (see, e.g. [29]). On the other hand, epitaxial misfit may equally induce large stress in the substrate (this phenomenon is used to measure stress in the film [11]). In the case when the substrate is rather thick, stress exerted by the film relaxes over a small distance $\sum^{\mathrm{AF}}$ in the near-surface layer of AF. For AFs with large magnetoelastic coupling, this surface stress can produce an additional magnetic anisotropy, which we will call a surface anisotropy.

Phenomenological description of this effect is based on the analysis of the Helmholtz free energy potential $G$, which includes elastic $f_{e}$ and magnetoelastic $f_{m e}^{\mathrm{AF}}$ energy of AF using antiferromagnetic vector $\mathbf{L}$ and components of stress tensor $\hat{\sigma}$ as the internal parameters:

$$
G=\int_{\mathrm{AF}}\left(f_{m e}^{\mathrm{AF}}+f_{e}\right) d V .
$$

In the simplest case of a cubic crystal, the elastic energy density $f_{e}$ takes a form

$f_{e}=$

$=\frac{s_{11}}{2}\left[\sigma_{x x}^{2}+\sigma_{y y}^{2}+\sigma_{z z}^{2}\right]+s_{12}\left[\sigma_{x x} \sigma_{y y}+\sigma_{y y} \sigma_{z z}+\sigma_{z z} \sigma_{x x}\right]+2 s_{44}\left[\sigma_{x y}^{2}+\sigma_{y z}^{2}+\sigma_{z x}^{2}\right]$,

where we turned from strains to stresses using the Hooke's law. Compliances $s_{i k}$ are expressed through the elastic moduli $c_{i k}$ in a usual way:

$$
s_{11}=\frac{c_{11}+c_{12}}{\left(c_{11}-c_{12}\right)\left(c_{11}+2 c_{12}\right)}, s_{12}=-\frac{c_{12}}{\left(c_{11}-c_{12}\right)\left(c_{11}+2 c_{12}\right)}, s_{44}=\frac{1}{c_{44}} \text {. }
$$


Density of magnetoelastic energy $f_{m e}$ can be written as

$$
\begin{aligned}
f_{m e}^{\mathrm{AF}} & =f_{\mathrm{exch}}+\frac{b_{1}^{\mathrm{AF}}}{c_{11}-c_{12}}\left(\sigma_{x x} L_{x}^{2}+\sigma_{y y} L_{y}^{2}+\sigma_{z z} L_{z}^{2}\right)+ \\
& +2 \frac{b_{2}^{\mathrm{AF}}}{c_{44}}\left(L_{x} L_{y} \sigma_{x y}+L_{y} L_{z} \sigma_{y z}+L_{z} L_{x} \sigma_{z x}\right),
\end{aligned}
$$

where $b_{1,2}^{\mathrm{AF}}$ are magnetoelastic coupling coefficients of a cubic $\mathrm{AF}$, and far from the Néel temperature, AF vector can be normalised, so $|\mathbf{L}|=1$. The first term in (12) describes a possible non-isomorphic contribution, which arises from the space dependence of the exchange interactions, described by a coefficient $B_{0}^{\mathrm{AF}}$. It depends on the specific type of AF. For example, for a single-domain NiO, it can be expressed as

$$
f_{\text {exch }}=\frac{B_{0}^{\mathrm{AF}}}{c_{44}}\left(\sigma_{x y}+\sigma_{y z}+\sigma_{z x}\right) \mathbf{L}^{2} .
$$

In the presence of the FM coverage, the AF substrate exerts a surface stress $\widehat{\tau}^{\mathrm{AF}}$ opposite to the surface stress in the FM film $\widehat{\tau}^{\mathrm{F}}$ :

$$
\widehat{\tau}^{\mathrm{AF}} \equiv \int \hat{\sigma} d z=-\widehat{\tau}^{\mathrm{F}} .
$$

$z$-axis is directed along the film normal and integration is over the $\mathrm{AF}$ thickness. For a (001) cubic surface, $\widehat{\tau}^{\mathrm{F}}$ can be estimated from the misfit value $\varepsilon_{\mathrm{MF}}$ as follows:

$$
\tau_{x x}^{\mathrm{F}}=\tau_{y y}^{\mathrm{F}}=t_{\mathrm{F}}\left(c_{11}+c_{12}-\frac{c_{12}^{2}}{c_{11}}\right) \epsilon_{\mathrm{MF}},
$$

where $t_{\mathrm{F}}$ is the FM film thickness. Substituting (13) into free energy (9), we obtain a contribution from the FM/AF misfit as

$$
G_{\mathrm{eff}}=\int_{S} \frac{b_{1}^{\mathrm{AF}}}{\left(c_{11}-c_{12}\right)} \tau^{\mathrm{F}} L_{z}^{2} d S=\frac{1}{2} \int_{S} K_{\mathrm{S}}^{\mathrm{AF}} L_{z}^{2} d S,
$$

which could be associated with the surface/interface energy of AF. Effective constant

$$
K_{\mathrm{S}}^{\mathrm{AF}}=2 b_{1}^{\mathrm{AF}} \epsilon_{\mathrm{MF}}\left(1+2 \frac{c_{12}}{c_{11}}\right) t_{\mathrm{F}}
$$

is proportional to the product of magnetoelastic coupling coefficient of $\mathrm{AF}$ and misfit (or effective stress) in the FM layer.

The sign of $K_{S}^{\mathrm{AF}}$ and, hence, the character of the induced surface anisotropy, is defined by the relation between the sign of AF spontaneous 
striction and that of external stress. Let us suppose FM lattice constant is smaller than that of $\mathrm{AF}\left(\tau^{\mathrm{F}}>0\right)$. Then, AF surface exerts a compressive stress. According to the general Le Chatelier's principle, AF vector at the surface will rotate in a way, which reduces the external influence. In the case of positive striction (AF spontaneously elongates in spin direction), in-plane orientation of AF spins will be preferable $\left(K_{S}^{\mathrm{AF}}>0\right)$. It worth to mention that the analogous, magnetoelastic, mechanism related with the rotation of AF moments in near-surface region is responsible for the shape-induced magnetic anisotropy in AF nanoparticles [30].

\section{DISCUSSION}

The misfit-induced surface anisotropy can produce a noticeable rotation of $\mathrm{AF}$ spins in the vicinity of interface region. The most pronounced effect can be expected for $\mathrm{NiO}, \mathrm{CoO}$, and $\mathrm{LaFeO}_{3} \mathrm{AFs}$, in which the bulk AF vector makes some angle with (001) surface. Particularly, in $\mathrm{NiO}$ and $\mathrm{CoO}$, the $\mathrm{AF}$ spins are ordered in (111) planes (with small deflection in the case of $\mathrm{CoO}$ [31-33]), in which they can be easily rotated. An easy-axis is directed along $\langle 2 \overline{1} \overline{1}\rangle$ in $\mathrm{NiO}$ and $\langle 3 \overline{\mathbf{1}} \overline{\mathbf{1}}\rangle$ in $\mathrm{CoO}$, thus, for a cleaved (001) surface, AF moments have nonzero component perpendicular to the surface plane, as is observed for $\mathrm{NiO}$ crystal $[34,35]$.

Depositions of $\mathrm{Fe}$ and $\mathrm{Co}$ on $\mathrm{NiO}$, and $\mathrm{Fe}_{3} \mathrm{O}_{4}$ and $\mathrm{Co}$ on $\mathrm{CoO}$ produce compressive surface stress in AF (see Table 4).

For $\mathrm{NiO}$ and $\mathrm{CoO}$, the magnetoelastic constants $b_{1}^{\mathrm{AF}}$ are positive (as deduced from the data [24, 36]), so, as it follows from (15), (16), for all the mentioned FM/AF combinations, the preferable orientation of AF vector $\mathbf{L}$ is in the interface (001) plane. A compromise between the strong dipole-dipole anisotropy, which tends to keep AF moments close to (111) plane, and strain-induced surface anisotropy in (001) plane is the direction $[1 \overline{1} 0]$. Therefore, depending on the balance be-

TABLE 4. Bulk lattice parameters $\left(2^{\text {nd }}\right.$ column) and calculated interatomic distances at (001) surface of f.c.c. lattice ( $3^{\mathrm{d}}$ column) for different FM and AF (in $[\AA]$ ).

\begin{tabular}{c|c|c}
\hline & Bulk & (001) Surface \\
\hline Fe, b.c.c. & $2.866[26]$ & 4.053 \\
Co, f.c.c. & $3.544[26]$ & 3.544 \\
$\mathrm{Fe}_{3} \mathrm{O}_{4}$ & $8.398[3]$ & 4.199 \\
$\mathrm{NiO}$ & 4.177 & 4.177 \\
$\mathrm{CoO}$ & $8.508[3]$ & 4.254 \\
\hline
\end{tabular}


tween the bulk magnetic anisotropy and the induced surface anisotro-

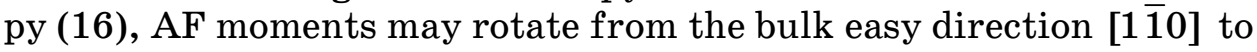
a smaller or larger angle. The effect should be obviously stronger for Co FM because of the large misfit value.

Experimentally this phenomenon was observed in [17], where deposition of $2 \mathrm{~nm}$ Co film on the (001) surface of $\mathrm{NiO}$ resulted in the total reorientation of $\mathrm{NiO}$ spins to [110] direction. An observed collinear alignment of $\mathrm{Co}$ and $\mathrm{NiO}$ spins in this system arises from both misfitinduced reorientation of $\mathrm{AF}$ moments and magnetostriction-induced uniaxial anisotropy in the FM layer.

A similar effect was observed in the $\mathrm{Fe}_{3} \mathrm{O}_{4} / \mathrm{CoO}$ multilayers [3], where an influence of the surface stress is much more pronounced. In this system, all of the AF Co moments lie along [110] or [1110] directions (depending on the AF domain type). This orientation does not vary with temperature, magnetic field and thickness of CoO layers.

Misfit-induced anisotropy of AF layer depends upon the internal stresses $\widehat{\tau}^{\mathrm{F}}$ in the adjacent ferromagnet, which could relax in the course of field cycling. Variation of stress, in turn, affects the domain structure of AF. Therefore, magnetoelastic mechanism can explain training effect (irreversible changes in configuration of AF domains), frequently observed in bilayers with multidomain state of AF in the ascast sample (see, e.g., Refs. [2, 37]).

In summary, we have studied the effect of magnetostriction on the properties of FM/AF coupled system. Spontaneous striction, which appears in antiferromagnet due to the $\mathrm{AF}$ ordering, can cause uniaxial in-plane anisotropy in the ferromagnetic film and set preferential easy axis of FM either along with or perpendicular to the orientation of AF vector. Competition between uniaxial anisotropy induced by longrange magnetostriction and short-range exchange mechanism results in different orientation of the FM easy-axis depending on the thickness of FM layer. Lattice misfit between FM and AF is a source of a magnetic surface anisotropy in AF substrate, which can cause rotation of AF moments in the near-surface region compared with their bulk orientation.

Authors acknowledge the financial support from the FP7SIMTECH.

\section{REFERENCES}

1. K. Li, Y. Wu, Z. Guo, Y. Zheng, G. Han, J. Qiu, P. Luo, L. An, and T. Zhou, J. Nanoscience and Nanotechnology, 7, No. 1: 13 (2007).

2. F. Radu, S. K. Mishra, I. Zizak, A. I. Erko, H. A. Dürr, W. Eberhardt, G. Nowak, S. Buschhorn, H. Zabel, K. Zhernenkov, M. Wolff, D. Schmitz, E. Schierle, E. Dudzik, and R. Feyerherm, Phys. Rev. B, 79, No. 18: 184425 (2009). 
3. Y. Ijiri, J. A. Borchers, R. W. Erwin, S.-H. Lee, P. J. van der Zaag, and R. M. Wolf, Phys. Rev. Lett., 80, No. 3: 608 (1998).

4. J. Nogués and I. K. Schuller, J. Magn. Magn. Mater., 192, No. 2: 203 (1999).

5. P. Miltenyi, M. Gierlings, J. Keller, B. Beschoten, G. Guntherodt, U. Nowak, and K. D. Usadel, Phys. Rev. Lett., 84, No. 18: 4224 (2000).

6. W. Zhu, L. Seve, R. Sears, B. Sinkovic, and S. S. P. Parkin, Phys. Rev. Lett., 86, No. 23: 5389 (2001).

7. C. L. Chien, V. S. Gornakov, V. I. Nikitenko, A. J. Shapiro, and R. D. Shull, Phys. Rev. B, 68, No. 1: 014418 (2003).

8. H. V. Gomonay and V. M. Loktev, Phys. Rev. B, 75, No. 17: 174439 (2007).

9. E. Folven, A. Scholl, A. Young, S. T. Retterer, J. E. Boschker, T. Tybell, Y. Takamura, and J. K. Grepstad, Phys. Rev. B, 84, No. 22: 220410 (2011).

10. Y. Takamura, R. V. Chopdekar, A. Scholl, A. Doran, J. A. Liddle, B. Harteneck, and Y. Suzuki, Nano Letters, 6, No. 6: 1287 (2006).

11. D. Sander, Reports on Progress in Physics, 62, No. 5: 809 (1999).

12. A. Enders, D. Sander, and J. Kirschner, J.Appl. Phys., 85, No. 8: 5279 (1999).

13. T. Gutjahr-Löser, D. Sander, and J. Kirschner, J. Magn. Magn. Mater., 220, No. 1: L1 (2000).

14. W. Wulfhekel, T. Gutjahr-Löser, F. Zavaliche, D. Sander, and J. Kirschner, Phys. Rev. B, 64, No. 14: 144422 (2001).

15. N. C. Koon, Phys. Rev. Lett., 78, No. 25: 4865 (1997).

16. F. Nolting, A. Scholl, J. Stöhr, J. W. Seo, J. Fompeyrine, H. Siegwart, J.-P. Locquet, S. Anders, J. Luning, E. E. Fullerton, M. F. Toney, M. R. Scheinfein, and H. A. Padmore, Nature, 405, No. 6788: 7679 (2000).

17. H. Ohldag, A. Scholl, F. Nolting, S. Anders, F. U. Hillebrecht, and J. Stöhr, Phys. Rev. Lett., 86, No. 13: 2878 (2001).

18. L. Malkinski, N. Cramer, A. Hutchison, R. Camley, Z. Celinski, and D. Skrzypek, J.Appl. Phys., 91, No. 10: 7242 (2002).

19. L. Malkinski, N. Cramer, A. Hutchison, R. Camley, Z. Celinski, D. Skrzypek, and R. B. Goldfarb, J. Magn. Magn. Mater., 240, Nos. 1-3: 261 (2002).

20. T. Yamada, J. Phys. Soc. Japan, 21, No. 4: 650 (1966).

21. S. C. Abrahams, R. L. Barns, and J. L. Bernstein, Solid State Com., 10, No. 4: 379 (1972).

22. J. Julliard and J. Nouet, Revue de Physique Appl., 10, No. 5: 325 (1975).

23. D. Skrzypek and J. Heimann, J. Magn. Magn. Mater., 139, Nos. 1-2: 102 (1995).

24. J. H. Greiner, A. E. Berkowitz, and J. E. Weidenborner, J.Appl. Phys., 37, No. 5: 2149 (1966).

25. G. Bochi, O. Song, and R. C. O'Handley, Phys. Rev. B, 50, No. 3: 2043 (1994).

26. Landolt-Börnstein. Numerical Data and Functional Relationships in Science and Technology: New Series. Group III. Crystal and Solid State Physics. Vol. 19. Magnetic Properties of Metals. Subvol.a. 3d,4d and 5d Elements, Alloys and Compounds (Berlin: Springer-Verlag: 1982).

27. H. D. Chopra, D. X. Yang, P. J. Chen, H. J. Brown, L. J. Swartzendruber, and W. F. Egelhoff, Jr., Phys. Rev. B, 61, No. 22: 15312 (2000).

28. T. Gredig, I. N. Krivorotov, and E. Dan Dahlberg, J.Appl. Phys., 91, No. 10: 7760 (2002).

29. R. H. Victora and J. M. MacLaren, Phys. Rev. B, 47, No. 17: 11583 (1993).

30. O. Gomonay, S. Kondovych, and V. Loktev, J. Magn. Magn. Mater., 354, No. 3: 
125 (2014).

31. W. L. Roth, Phys. Rev., 111, No. 3: 772 (1958).

32. G. A. Slack, J.Appl. Phys., 31, No. 9: 1571 (1960).

33. D. Herrmann-Ronzaud, P. Burlet, and J. Rossat-Mignod, J. Phys. C: Solid State Phys., 11, No. 10: 2123 (1978).

34. F. U. Hillebrecht, H. Ohldag, N. B. Weber, C. Bethke, U. Mick, M. Weiss, and J. Bahrdt, Phys. Rev. Lett., 86, No. 15: 3419 (2001).

35. A. Scholl, F. Nolting, J. Stöhr, T. Regan, J. Lüning, J. W. Seo, J.-P. Locquet, J. Fompeyrine, S. Anders, H. Ohldag, and H. A. Padmore, J. Appl. Phys., 89, No. 11: 7266 (2001).

36. T. Yamada, S. Saito, and Y. Shimomura, J. Phys. Soc. Japan, 21, No. 4: 672 (1966).

37. X. Fu, G. Cao, Y. Gao, Z. Wu, and J. Zhang, J. Modern Physics, 2, No. 10: 1187 (2011). 